\title{
Analiza występowania niezgodności spawalniczych w podstawach wież wiatrowych
}

\author{
Analysis of occurrence of welding imperfections \\ in the wind offshore project
}

\section{Streszczenie}

Artykuł przedstawia problematykę analizy kontroli jakości przy spawaniu wielkogabarytowych konstrukcji podstaw wież wiatrowych typu offshore. W pracy przedstawiono zagadnienia związane ze statystyką kontroli jakości dla jednego z typów fundamentowania wież wiatrowych. Wymagania odbiorowe konstrukcji fundamentu oprócz badań wizualnych i badań magnetyczno-proszkowych zostały uzupełnione wymaganiami badań ultradźwiękowych po realizacji montażu wielkogabarytowych elementów konstrukcji morskich wież wiatrowych. Praca zawiera analizę występowania niezgodności spawalniczych zaobserwowanych na 7 elementach ważących po 500 ton podstaw wież wiatrowych. Analizę przeprowadzono dla niezgodności wykrytych metodą ultradźwiękową po wykonaniu blisko 5 kilometrów spoin zrealizowanych na jednym z projektów zlokalizowanym na Morzu Północnym u wybrzeży Niemiec.

Słowa kluczowe: niezgodności; Offshore, MAG; Energia wiatrowa

\begin{abstract}
The article presents the analysis of the problems of quality control in welding large structures of the towers foundations of offshore wind. The paper presents issues related to statistical quality control for one type of foundation wind towers. Requirements of construction of the foundation should be checked by visual and magnetic testing and ultrasonic testing after the execution of the assembly of large structural elements of marine wind towers. The paper contains an analysis of the occurrence of imperfections observed at 7 elements, which every is 500 tons heavy. The analysis was carried out for welding imperfection detected by ultrasonic testing after nearly five kilometers joints completed in one of the projects located in the North Sea coast of Germany.
\end{abstract}

Keywords: imperfections; Offshore, MAG; wind energy

\section{Wstęp}

W obecnej chwili farmy wiatrowe budowane są w strefie brzegowej o głębokości wody do 50 metrów o projektowanych mocach pojedynczej jednostki do $5 \mathrm{MW}$, co przy zainstalowaniu parku 80 sztuk takich instalacji daje moc $400 \mathrm{MW}$. Trwają również prace nad zwiększeniem mocy generatora ponad zainstalowane dotychczas $5 \mathrm{MW}$.

W planach niemieckiego rządu zakładana jest budowa na Morzu Północnym i Bałtyckim około 40 tzw. farm wiatrowych, które razem mają mieć zdolność generować moc w założeniach projektowych około 12000 MW. Określa się, że energii elektrycznej wyprodukowanej z siły wiatru ma wystarczyć dla jednej czwartej niemieckich gospodarstw domowych.

Instalacja wież wiatrowych na morzu umożliwia uzyskanie pełnej mocy generatora, gdyż wiatr morski wieje o wiele silniej niż na lądzie. Dlatego turbiny wiatraków mogą pracować przez 7500 godzin rocznie, dla porównania na lądzie wiatr wieje jedynie maksymalnie do 3000 godzin. Jedna morska farma wiatrowa (w Polsce $300 \mathrm{MW}$ ) może wyprodukować tyle prądu, ile dwie-trzy lądowe farmy wiatrowe tej samej mocy. Współczynnik efektywność pracy wynosi od
36 do $50 \%$. W 2008 roku określono, iż energetyka wiatrowa odpowiada za 2,5\% wytworzonej energii na świecie, a niektóre kraje jak Dania osiągają do 30 \% energii ze źródeł odnawialnych. Inwestycje w „zieloną energię” wymuszają regulacje unijne, które wymagają aby do 2020 roku - $20 \%$ energii powinno być wytworzone z odnawialnych źródeł.

Zastosowanie nowoczesnych rozwiązań i wykorzystanie energii wiatru na morzu pozwala na uzyskanie mocy do $5 \mathrm{MW}$, a w przyszłości planowany jest wzrost mocy generatora na-

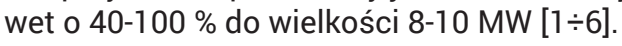

\section{Fundamenty wież wiatrowych}

Fundament jest podstawą do budowy wieży elektrowni wiatrowej typu offshore i może mieć różne warianty konstrukcyjne, które zostały przedstawione na rysunkach $1 \div 3$. Fundamenty wież wiatrowych dla uporządkowania zostały określone jako: monopile (rys.1a), triod (rys.1b), jacket(rys.1c), compilant (rys.1d), barge floater (rys.1e), tension leg platform (rys.1f), span floater structure (rys.1f).

Dr inż. Robert Bęczkowski - Politechnika Częstochowska.

Autor korespondencyjny/Corresponding author. rbeczkowski@spaw.pcz.pl 


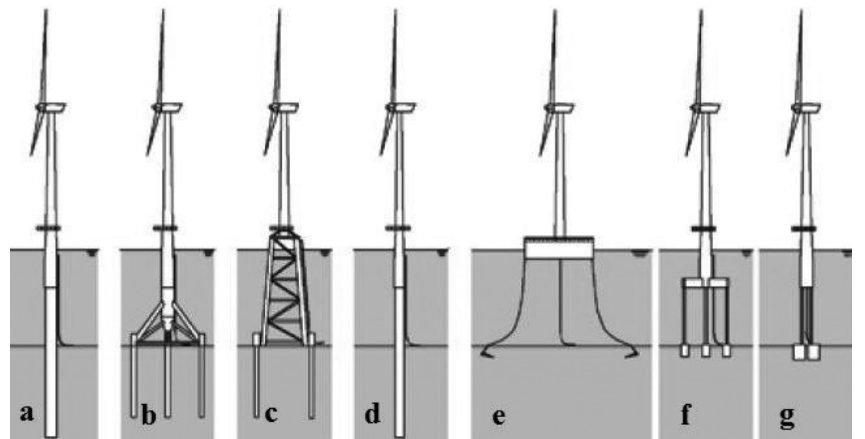

Rys. 1. Fundamenty wież wiatrowych

Fig. 1. The foundations of wind towers

Na rysunku 2 przestawiono fundamenty typu: a) Gravity Base Structures, b) Monopile, c) Tripod, d) Tripod Support Structure. Na rysunku 3 przedstawiono analizowaną konstrukcję podczas montażu z użyciem specjalnej barki montażowej $[1 \div 5]$.

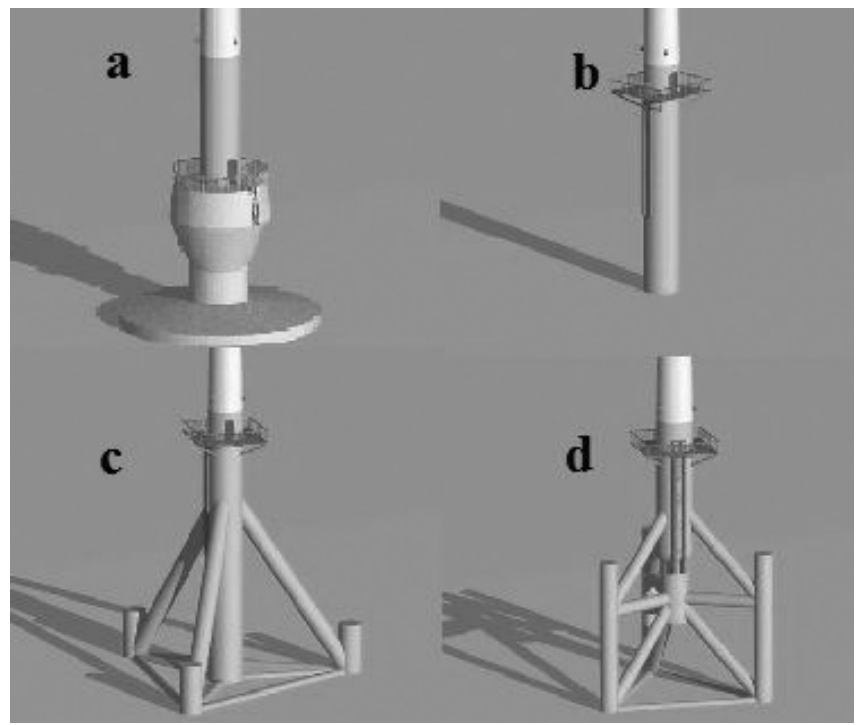

Rys. 2. Betonowe i stalowe fundamenty wież wiatrowych Fig. 2. Concrete and steel of the foundations of wind towers

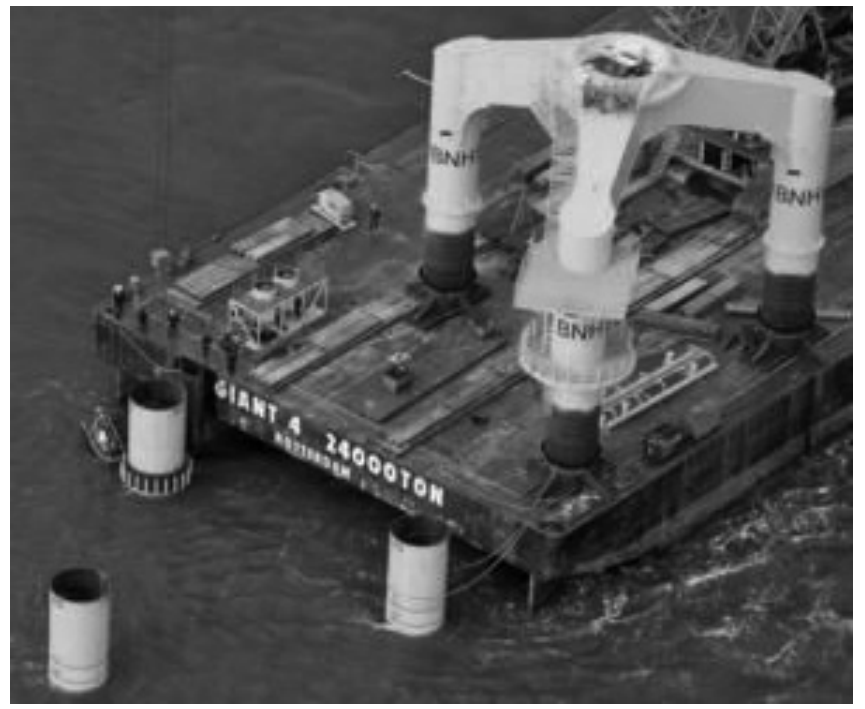

Rys. 3. Podstawa wieży wiatrowej typu Triple

Fig. 3. The foundations of wind towers of the type Triple

\section{Podstawy typu TRIPILE}

Analizie zostanie poddana konstrukcja podstawy typu Tripile zbudowana modułowo z kilku elementów umożliwia- jących transport zarówno morski jak i samochodowy. Dostarczone do montażu ostatecznego moduły o wadze dochodzącej do 80 ton, umieszczane są na specjalnej platformie, gdzie są ustawiane z wykorzystaniem zaawansowanych technik geodezyjnych z wykorzystaniem sygnału satelitarnego celem zapewnienia wysokiej powtarzalności produkcji szczególnie rozstawu poszczególnych elementów łączących. Do montażu wykorzystano halę montażową wyposażoną w dwa specjalne dźwigi bramowe o udźwigu 300 ton, dający możliwość wykonania transportu tandemowego przy zastosowaniu specjalnej trawersy transportowej. Takie połączenie daje możliwość przenoszenia zmontowanej podstawy o masie blisko 500 ton. Główny podział (rys.4) tripile`a opiera się o rurę centralną (1), do której są montowane trzy łączniki (2). Tak złożony i uzbrojony element ustawia się na trzech palach (3), następnie uzbraja się w elementy usztywniające wewnętrzne i zewnętrzne oraz osprzęt $(4,5)$. Masa każdego z głównych elementów wynosi około 60-80 ton. Podział konstrukcji pokazano na rysunku 4 [2].

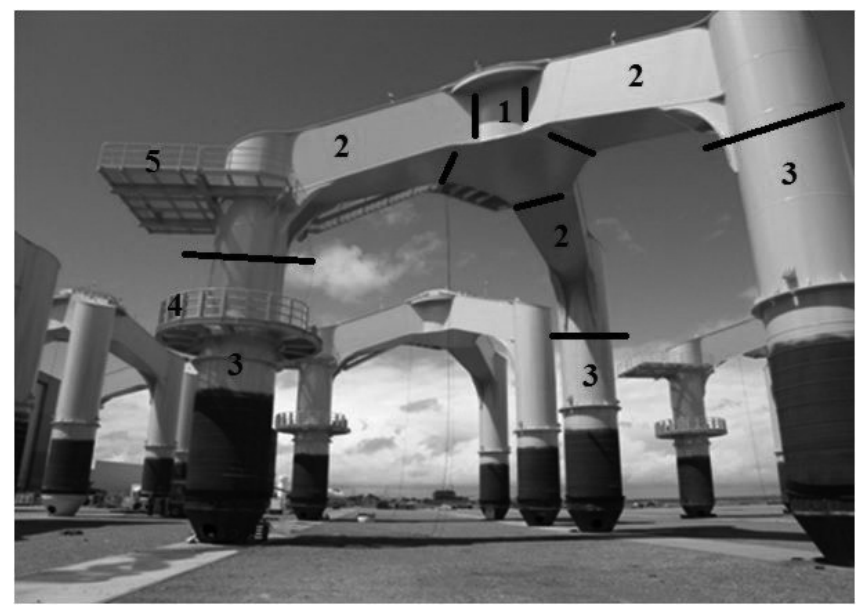

Rys. 4. Podział konstrukcji

Fig. 4. The division of construction

Ze względu na różne obciążenia elementów konstrukcyjnych elementy wykonywano ze stali różnych gatunków (S235, S355 oraz S420). Przedział grubości zastosowanych materiałów zawarty jest w przedziale od 10 do $80 \mathrm{~mm}$. Grubość elementów nośnych mieści się w zakresie 50-70 mm, użebrowań wewnętrznych 10-20 mm, użebrowań zewnętrznych $30-80 \mathrm{~mm}$. Celem zabezpieczenia materiałów przed niekorzystnymi zmianami strukturalnymi wynikających z dużych szybkości stygnięcia oraz trudności z wykonaniem warstw przetopowych (miedzy innymi ze względu na znaczne usztywnienia konstrukcji) zastosowano podgrzewanie wstępne. Do podgrzewania konstrukcji wykorzystano nagrzewnice indukcyjne $z$ zastosowaniem elastycznych elementów grzejnych. Zastosowanie indukcyjnych nagrzewnic pozwoliło na precyzyjne zadanie temperatury wstępnego podgrzewania oraz kontrolowaniu przebiegu procedury grzewczej tj. utrzymanie temperatury przez cały czas trwania procesu spawania oraz precyzyjnym studzeniem po spawaniu z zadaną prędkością. W przypadku niedotrzymania warunków przygotowania procesu spawania, pojawiały się na powierzchni wskazania niezgodności w procesie kontroli z zastosowaniem badań magnetyczno-proszkowych (rys. 5) lub powodowały pękanie warstw przetopowych w wyniku zwiększonej szybkości odbioru ciepła $[7,8]$.

Stosowane materiały spawalnicze w budowie elementów wież wiatrowych powinny zapewniać połączenie spawane o żądanej jakości gwarantujące udarność w obniżonej temperaturze. Wykorzystano do łączenia elementów spawanie półautomatyczne w osłonie gazowej M21 według PN EN ISO 14175 
( $\left.\mathrm{Ar} / \mathrm{CO}_{2} 75 \% / 25 \%\right)$, natężenie przepływu gazu osłonowego 15$18 \mathrm{l} / \mathrm{min}$. Jako materiałów dodatkowych użyto drutu z rdzeniem rutylowym (136) o oznaczeniu T 5061 Ni P M1 H5 wykorzystanym do spawania warstw graniowych w pozycjach PA, PC, PE oraz drutu z rdzeniem metalicznym (138) o oznaczeniu T 504 Z M M1 H5 do spawania w pozycjach PF, którym wykonywano ścieg graniowy i wypełnienie rowka oraz dla pozycji PA, PC, PE do wypełniania rowka $[9,10]$.

W celu ułatwienia procesu spawania i zwiększenia wydajności zastosowano podkładki ceramiczne. W zależności od dostępności miejsca spawania stosowano podkładki: okrągłe, płaskie, jak i trójkątne w przypadku większych szczelin. Generalną zasadą doboru i stosowania podkładek ceramicznych jest wielkość szczeliny wynikająca z gabarytów zewnętrznych elementów oraz możliwość właściwego przygotowania przez szlifowanie, frezowanie, czy żłobienie elektrodą węglową brzegów elementów do spawania kolejnych warstw.

Do montażu przygotowano żebra montujące i ustalające wykonane przy wykorzystaniu technik laserowych. Takie przygotowanie w znaczny sposób skraca proces montażu elementów zarówno na etapie wstępnego przygotowania jak i ostatecznego uzbrajania podstawy.

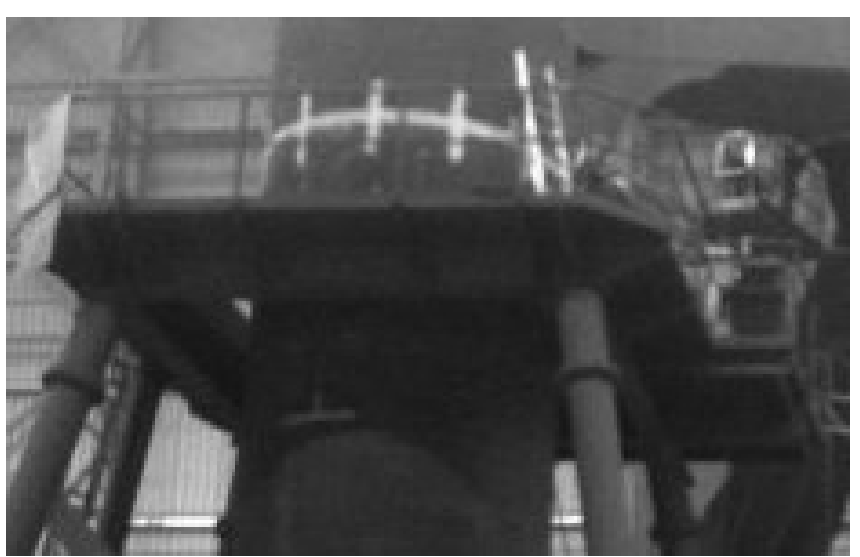

Rys. 5. Proces kontroli niezgodności powierzchniowych

Fig. 5. Process control welding imperfection on the surface

\section{Kontrola jakości}

Kontrolę jakości spoin prowadzono wykorzystaniem laboratorium spawalniczego posiadającego uprawnienia zgodnie z PN EN ISO 17025 w zakresie badań wizualnych, magnetyczno-proszkowych i ultradźwiękowych. [11]

Analizie poddano proces kontroli metodą ultradźwiękową spoin czołowych około 700 metrów bieżących spoin wykonywanych na etapie końcowego montażu elementów. Kontrola obejmowała $100 \%$ połączeń i każdorazowo było identyfikowane zarówno miejsce, jak i spawacz lub spawacze wykonujący dane połączenie poprzez podanie informacji o numerze projektu, części, pozycji łączonych, daty zgłoszenia do odbioru i ewentualne dane o niezgodnościach takich jak: odległość od punktu bazowego, głębokość i długość niezgodności oraz numer identyfikacyjny spawacza wraz oceną ostateczną odbioru. Na podstawie zebranych danych z protokołów badań ultradźwiękowych z wykonania blisko 5 kilometrów spoin można stwierdzić, iż wykonano 105 metrów długości niezgodności zidentyfikowanych w spoinach czołowych na wszystkich analizowanych elementach. Długość poprawek daje średnio 2,01\% korekt złącz spawanych w odniesieniu do całkowitej długości spoin (5000 m). Wskaźnik korekt potwierdza, iż cel jakościowy założony na początku procesu wytwarzania na poziomie 3\% i zweryfikowany do $2 \%$ w trakcie nabierania doświadczenia (średniorocznie 2,5\%) został zrealizowany.
W odniesieniu do jednego pięćset tonowego fundamentu wytwarzanego na końcowym etapie montażu średnio na elemencie zidentyfikowano 32 niezgodności, w tym 17 niezgodności dotyczyło spawania w pozycji PF, 9 niegodności w pozycji PC i 6 poprawek w pozycji PA/PE. Analizę prowadzono z podziałem na pozycje PA/PE, PC, PF. Pozycja PA/PE wynikała z rozwiązań występujących na projekcie, gdzie część prac była wykonywana w pozycji PA i PE. Procentowo za najwięcej poprawek odpowiada pozycja PF, która generowała aż 52\% wszystkich niezgodności, w dalszej kolejności PC oraz łącznie PA/PE. Szczegółowe wyniki zawiera tablica I. W tablicy II zawarto analizę długości niezgodności i określono procentowo udział występowania w zależności od pozycji spawania.

Tablica I. Udział procentowy niezgodności w projekcie

Table I. The share of the percentage of welding imperfection in the project

\begin{tabular}{|c|c|c|c|}
\hline Pozycja spawania & PA/PE & PC & PF \\
\hline $\begin{array}{c}\text { Ilość niezgodności } \\
\text { /szt./ }\end{array}$ & 6 & 9 & 17 \\
\hline $\begin{array}{c}\text { Procent } \\
\text { niezgodności } \\
\text { /\%/ }\end{array}$ & 18,75 & 28,125 & 53,125 \\
\hline
\end{tabular}

Tablica II. Udział długości niezgodności w projekcie

Table II. The share of the length of welding imperfection in the project

\begin{tabular}{|c|c|c|c|}
\hline Pozycja spawania & PA/PE & PC & PF \\
\hline $\begin{array}{c}\text { Długość } \\
\text { niezgodności } \\
\text { /mm/ }\end{array}$ & 2010 & 7785 & 5125 \\
\hline $\begin{array}{c}\text { Procent } \\
\text { niezgodności } \\
\text { /\%/ }\end{array}$ & 13,47 & 52,18 & 34,35 \\
\hline
\end{tabular}

Z analizy danych z tablic I i II można wyciągnąć wnioski, iż pozycja PF generuje największą ilość niezgodności, a ich średnia długość wynosi $301 \mathrm{~mm}$. W przypadku połączonych pozycji PA/PE niezgodności jest najmniej ilościowo, a średnia długość niezgodności wynosi $335 \mathrm{~mm}$, ale już w przypadku spawania w pozycji PC pomimo 9 zidentyfikowanych niezgodności to średnia długość niezgodności wynosi aż $865 \mathrm{~mm}$, blisko 3 razy więcej niż w przypadku pozostałych pozycji. Jednakże na wielkość tego wskaźnika wpływa każdorazowo proces wykonania trzech obwodów o średnicy 3000 mm i grubości materiału 70 mm, co jest procesem żmudnym dla spawacza. Zjawisko to zostało zaobserwowane w projekcie i podjęto próby mechanizacji wykonania tego połączenia.

Poddając analizie częstotliwość oraz miejsc występowania niezgodności istnieje możliwość sprawnego zarządzania procesem montażu i spawania. Informacje dostarczane z procesu kontroli pozwalają na szybką interwencję służb technicznych w celu znalezienia optymalnych rozwiązań. 


\section{Podsumowanie}

Kontrolowanie i analiza wyników badań pozwala na szybkie reagowanie na problemy wynikające z prac w wymuszonych pozycjach.

Odpowiednie warunki przygotowania złączy oraz zachowanie odpowiedniej kolejności spawania minimalizują straty czasu na trudne szlifowanie lub wycinanie złącz.

Stosowanie procesu samokontroli z wykorzystaniem badań penetracyjnych szczególnie warstw przetopowych minimalizuje ilość napraw, co jest szczególnie istotne przy elementach, których grubość dochodzi do $80 \mathrm{~mm}$.

W przypadku grubych elementów nie długość niezgodności jest istotna, lecz ich ilość. Każdorazowo niezgodność wymusza działanie naprawcze z zachowaniem zasady, iż należy zrobić odpowiednie wprowadzenie do usunięcia niezgodności oraz wyjście. W przypadku krótkich niezgodności potrafi to zwielokrotnić długość naprawianą. Powoduje to wydłużenie czasu i kosztu przygotowania elementów do spawania w tym przypadku konieczności ponownego nagrzania przygotowanego złącza do osiągnięcia minimalnej temperatury wstępnego podgrzewania.

Założona polityka jakościowa determinująca określone poziomy napraw wymaga pełnego zaangażowania zarówno na etapie przygotowania elementów do spawania jak i wykonawstwa. Świadomość problemów, jakie mogą wystąpić i sposób reakcji na powstałe problemy zmniejsza ilość napraw, a co za tym idzie zwiększa zdolności wytwórcze poprawiając efektywność prac.

\section{Literatura}

[1] M.Karimirad; Offshore Energy Structures, Springer 2014, DOI: 10.1007/9783-319-12175-8.

[2] www.bard-offshore.de -z dnia 21.03.2016.

[3] www.eewspc.com -z dnia 21.03.2016.

[4] http://www.upwind.eu- z dnia 20.03.2016.

[5] http://www.offshorewindenergy.org -z dnia 20.03.2016.

[6] http://cleantechnica.com - dnia 21.03.2016.

[7] G. Rogalski, J. Łabanowski, D. Fydrych, J. Tomkow; Bead-on-plate weIding on S235JR steel by underwater local dry chamber process, Polish Maritime Research 2(82) 2014 Vol 21; pp. 58-64 DOI: 10.2478/pomr2014-0020.
[8] G. Rogalski, J. Łabanowski, D. Fydrych,J. ; Weldability of high strength steels in wet welding conditions, Polish Maritime Research 2(78) 2013 Vol 20; pp. 67-73; DOI:10.2478/pomr-2013-0018.

[9] Katalogi materiałów spawalniczych firmy Drahtzug Stein

[10] PN-EN ISO 14175:2009 Materiały dodatkowe do spawania -- Gazy i mieszaniny gazów do spawania i procesów pokrewnych.

[11] PN-EN ISO/IEC 17025:2005; Ogólne wymagania dotyczące kompetencji laboratoriów badawczych i wzorcujących. 